\title{
Notes on the vocalizations of Asian Paradise-flycatcher (Terpsiphone paradisi)
}

Peter Boesman

In the following we briefly analyze and compare voice of the different races of Asian Paradise-flycatcher (Terpsiphone paradisi). We also try to quantify the extent of any vocal differences using the criteria proposed by Tobias et al. (2010), as a support for taxonomic review. We have made use of sound recordings available on-line from Xeno Canto (XC).

There are 14 subspecies recognized, which we have grouped into four clusters. We will only compare song of these groups as call notes are very similar for all members of the genus Terpsiphone.

\section{Chinese group (incei)}

Only a single recording found of short song and calls:

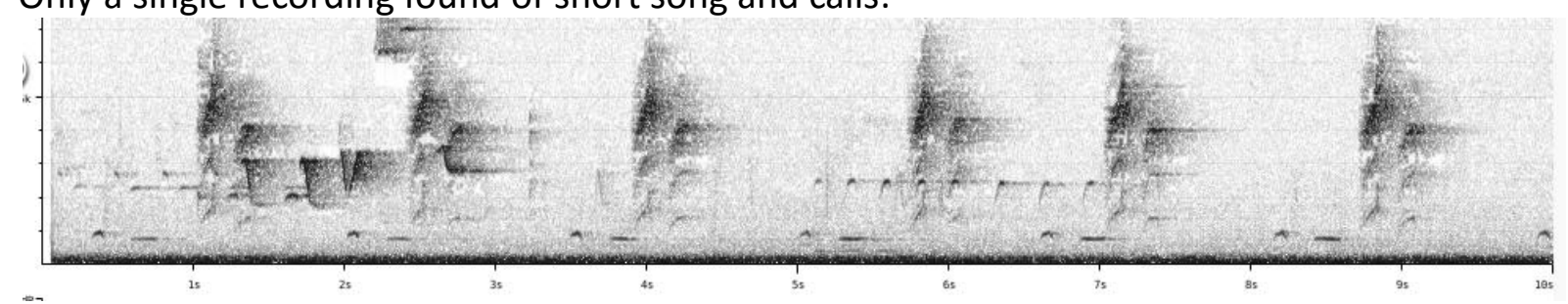

Indian Group (paradisi, leucogaster, ceylonensi) paradisi (Goa)

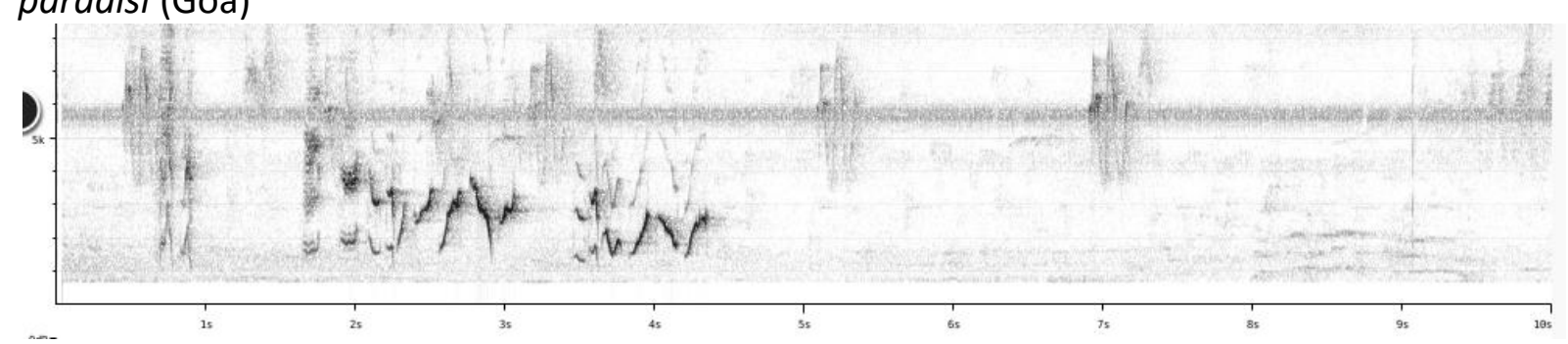

leucogaster

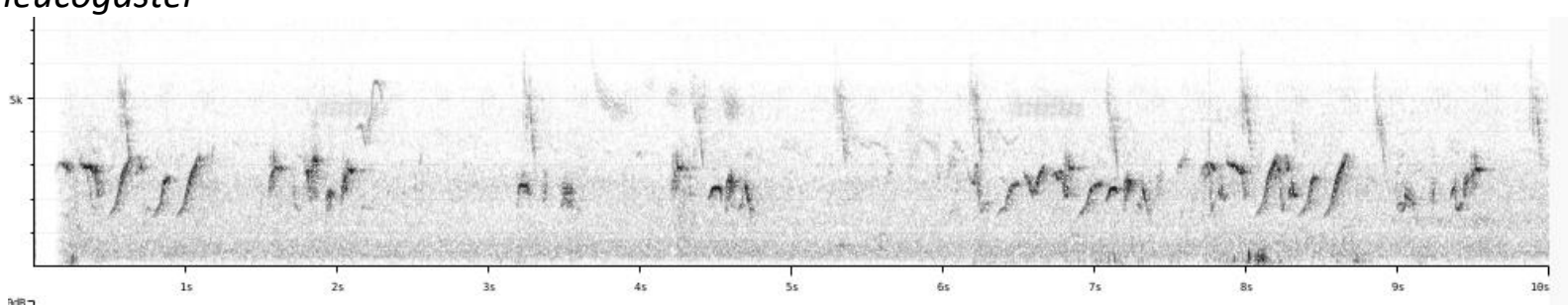

ceylonensi

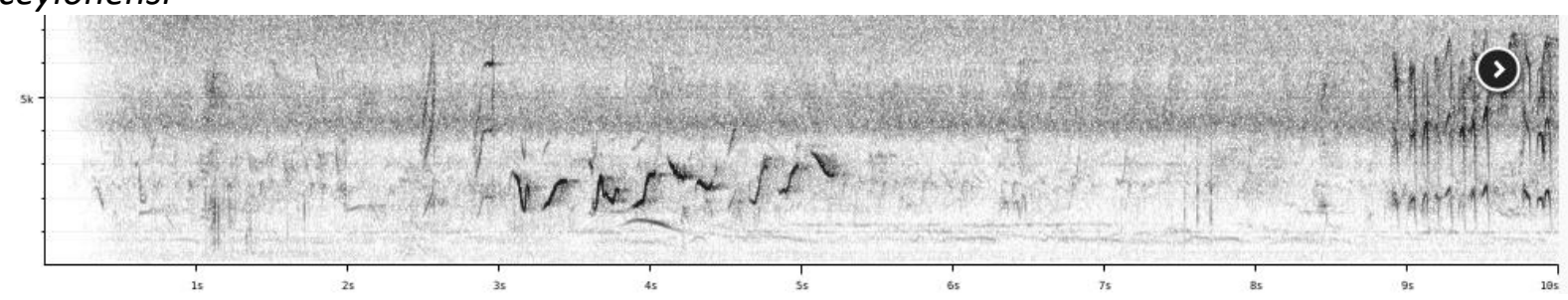




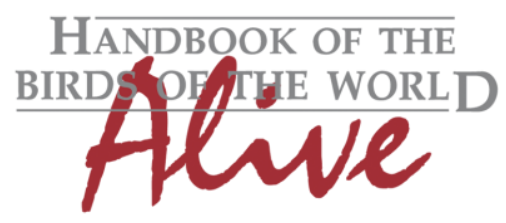

\section{ORNITHOLOGICAL NOTES}

SE Asian group Terpsiphone affinis (all other races)

affinis (peninsular Malaysia)

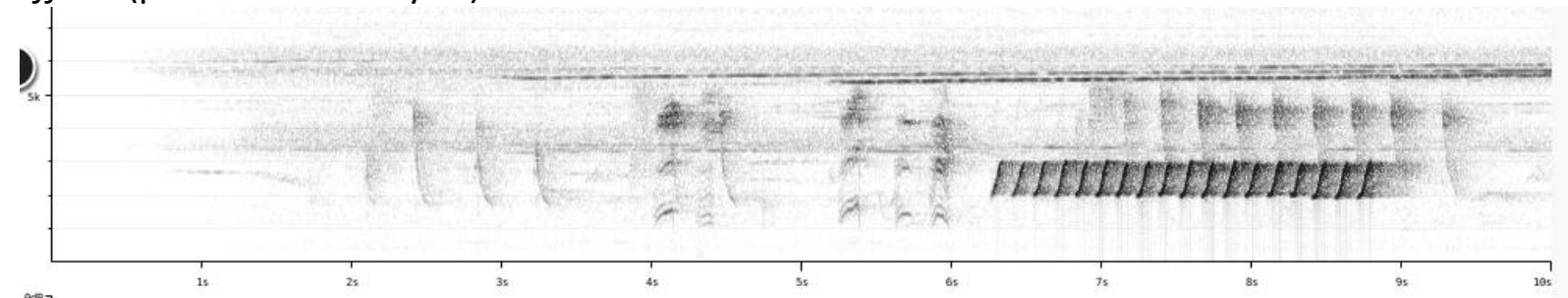

Thailand

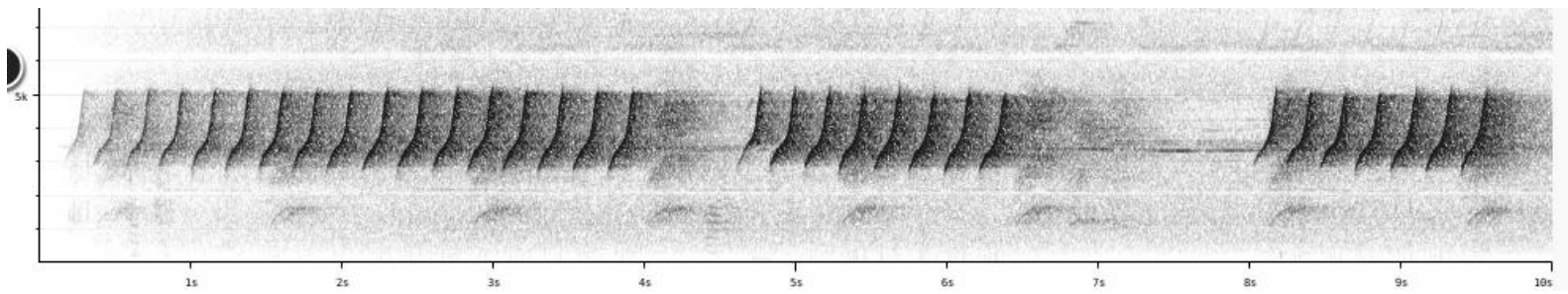

borneensis (Borneo)

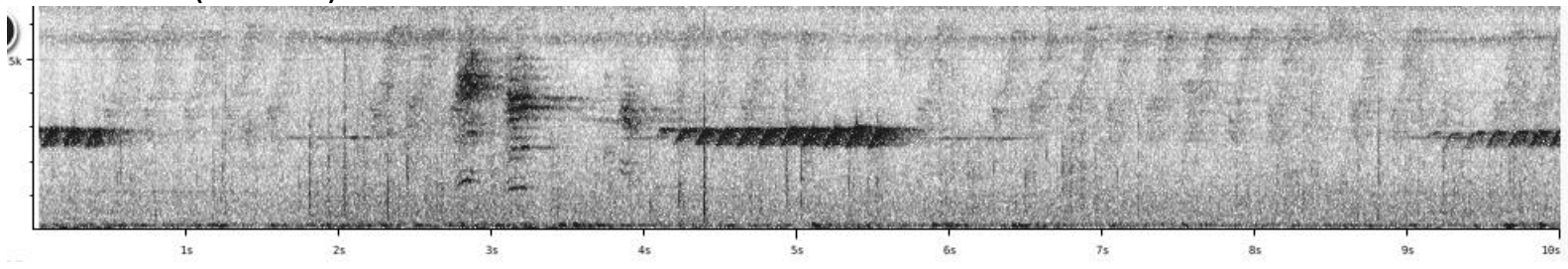

Lesser Sunda group (floris, sumbaensis) $(n=1)$

floris

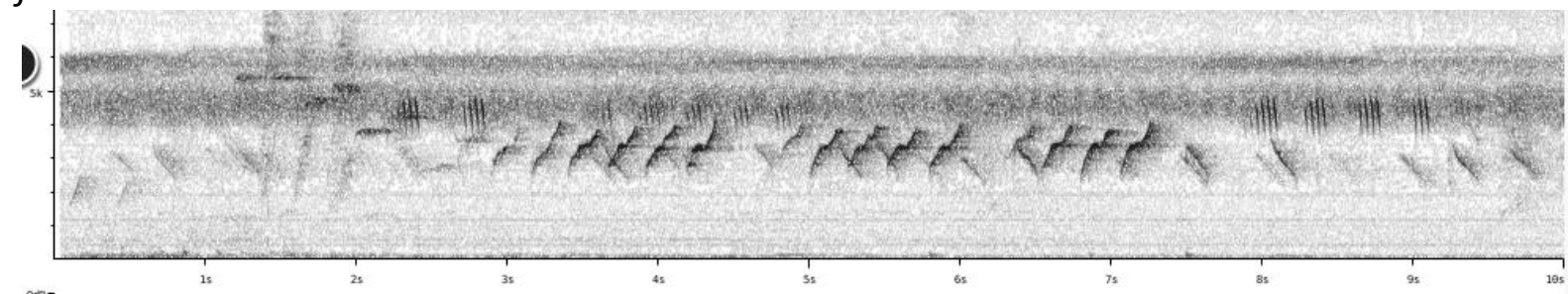

Voice of SE Asian and Lesser Sunda group is clearly different from previous two groups: song is a series of repeated single upslurred notes.

Chinese and Indian group on the contrary have a very different song, a short melodious phrase consisting of many different whistles.

Therefore, vocal difference can be easily quantified: score for SE Asian and Lesser Sunda group vs Indian and Chinese group is 4 based on a single note repeated many times (typically more than 10) vs short phrase of all different notes (no repeats).

The single recording of incei is not sufficient to determine consistent vocal differences vs Indian group.

The single recording of floris suggests that the pace is somewhat slower than closest races borneensis and affinis, and the note shape is rather irregular unlike mentioned races. This should however be confirmed by more recordings. 
As a final remark, some recordings (XC105098-XC105100) of race floris are very different, but ID apparently has been questioned.

This note was finalized on 17th February 2016, using sound recordings available on-line at that moment. We would like to thank in particular the sound recordists who placed their recordings of song for this species on XC: Patrik Åberg, Chandu Bandi, Peter Boesman, Niels Poul Dreyer, David Edwards, Johannes Fischer, Greg Irving, Frank Lambert, Eveny Luis, John V Moore, Mike Nelson, Scott Olmstead, Conrad Pinto and Sudipto Roy.

\section{References}

Tobias, J.A., Seddon, N., Spottiswoode, C.N., Pilgrim, J.D., Fishpool, L.D.C. \& Collar, N.J. (2010). Quantitative criteria for species delimitation. Ibis 152(4): 724-746.

\section{Recommended citation}

Boesman, P. (2016). Notes on the vocalizations of Asian Paradise-flycatcher (Terpsiphone paradisi). HBW Alive Ornithological Note 200. In: Handbook of the Birds of the World Alive. Lynx Edicions, Barcelona. (retrieved from http://www.hbw.com/node/932146 on 30 August 2016). 